\title{
ESTUDO DE VIABILIDADE ECONÔMICA E FINANCEIRA PARA PRODUÇÃO ARTESANAL DE QUEIJO CABACINHA NA REGIÃO DO VALE DO JEQUITINHONHA - MG
}

\section{Economic and financial viability study for artisanal production of Cabacinha cheese in Vale do Jequitinhonha region - MG}

\section{Bruna Randi Souza ${ }^{I}$, Christiano Vieira Pires ${ }^{I}$, Juliana Cristina Sampaio Rigueira Ubaldo ${ }^{I}$, Giann Braune Reis ${ }^{l}$, Felipe Machado Trombete ${ }^{l *}$}

\section{RESUMO}

O Queijo Cabacinha é um produto de grande importância na região do Vale do Jequitinhonha-MG, contribuindo para a geração de trabalho e renda para agricultores familiares. Ainda pouco conhecido, é elaborado de forma caseira e não padronizada por grande parte dos agricultores, o que pode comprometer a qualidade e segurança do produto. Nesse sentido, a formalização da produção através de uma agroindústria familiar, respeitando os aspectos técnicos quanto as instalações e processamento, pode ser uma alternativa para a sua produção de forma segura e com qualidade. Esse trabalho objetivou realizar um estudo de viabilidade econômica e financeira de um projeto de agroindústria familiar para a fabricação do queijo artesanal Cabacinha, em condições adequadas de boas práticas de fabricação, visando agregar valor e qualidade a produção local. Foram abordados os aspectos mercadológicos e operacionais da produção, indicando as condições que devem ser respeitadas para as instalações e para o processamento do leite até sua transformação no queijo. No projeto financeiro, foi elaborada uma projeção do fluxo de caixa da empresa para os primeiros anos de atividade, bem como calculados a lucratividade, rentabilidade, Valor Presente Líquido, Taxa Interna de Retorno e o Payback. Pode-se concluir que é viável o investimento para a construção da queijaria artesanal, visando a produção em regime de agroindústria familiar de pequena escala no Vale do Jequitinhonha. A produção irá proporcionar ao produtor rural maior valorização do leite, contribuindo

1 Universidade Federal de São João del-Rei, Campus Sete Lagoas, Departamento de Engenharia de Alimentos, Rodovia MG424, km 47, 35701-970, Sete Lagoas, MG, Brasil. E-mail: trombete@ufsj. edu.br

* Autor para correspondência

Recebido / Received: 28/09/2019

Aprovado / Approved: 24/03/2020 
para a produção de um alimento seguro para o consumidor, bem como, respeitando e fortalecendo as tradições locais.

Palavras-chave: queijo artesanal; agroindústria familiar; norte de Minas Gerais; projeto agroindustrial.

\begin{abstract}
Cabacinha cheese is a product of great importance in the Vale do Jequitinhonha - MG region, contributing to the generation of work and income for family farmers. It is a product still little known, being elaborated on the homemade form by a great part of the farmers, which can compromise product quality and safety. In this way, the formalization of production through a family agroindustry, respecting the technical aspects regarding facilities and processing, can be an alternative to produce a safe and quality cheese. This work aimed to carry out a financial and economic feasibility study of a family agroindustry project for the processing of Cabacinha cheese, under appropriate conditions of good manufacturing practices, respecting the current legislation and adding value and quality to local production. The marketing and operational aspects of production are discussed, indicating the conditions that must be respected for the construction of the agroindustry and the processing of the milk until its transformation into the Cabacinha cheese. In the financial project, a projection of the company's cash flow was prepared for the first years of activity, as well as calculated the profitability, Net Present Value, Internal Rate of Return, and discounted payback. It can be concluded that the financial investment for the construction of artisanal cheesemaking is feasible, aiming the production of Cabacinha cheese in small-scale family agroindustry, in the Vale do Jequitinhonha region. The production will give the rural producers higher financial returns, contributing to the production of a food safe to consume, as well as respecting and strengthening local traditions.
\end{abstract}

Keywords: artisanal cheese; family agroindustry; North of Minas Gerais; agroindustrial project.

\section{INTRODUÇÃO}

Os queijos Minas artesanais são queijos de produção histórica e tradicional, produzidos a partir de leite cru e com características específicas das regiões produtoras, sendo responsáveis pela geração de trabalho e renda de várias famílias de produtores rurais (DORES; FERREIRA, 2012). No Brasil, o estado de Minas Gerais é o maior produtor de queijos artesanais, com produção anual estimada em 220 mil toneladas por ano, fabricado por cerca de 9 mil famílias (EMATER, 2017).
O modo de fazer queijo Minas artesanal foi registrado como Patrimônio Cultural Imaterial Brasileiro pelo Instituto do Patrimônio Histórico e Artístico Nacional em 2008 (IPHAN, 2014). De acordo com o Instituto Mineiro de Agropecuária (IMA, 2002), pela Portaria $n^{\circ} 523$, de 03 de julho de 2002, o queijo Minas artesanal é definido como:

[...] o produto elaborado, conforme a tradição histórica e cultural da região do Estado onde for produzido, a partir do leite cru, hígido, integral, recém ordenhado, retirado e beneficiado na 
Tabela 1 - Regiões produtoras de Queijo Artesanal e cidades autorizadas, cadastradas no Instituto Mineiro de Agropecuária (IMA)

\begin{tabular}{|c|c|c|}
\hline $\begin{array}{l}\text { Região } \\
\text { produtora }\end{array}$ & Identidade & Cidades cadastradas \\
\hline Canastra & $\begin{array}{l}\text { Queijo Minas } \\
\text { Canastra }\end{array}$ & $\begin{array}{l}\text { Bambuí, Delfinópolis, Medeiros, Piumhi, São Roque de } \\
\text { Minas, Tapiraí, Vargem Bonita, São João Batista do Glória. }\end{array}$ \\
\hline Araxá & $\begin{array}{l}\text { Queijo Minas } \\
\text { Araxá }\end{array}$ & $\begin{array}{l}\text { Araxá, Campos Altos, Conquista, Ibiá, Pratinha, } \\
\text { Pedrinópolis, Perdizes, Sacramento, Santa Juliana, Tapira, } \\
\text { Uberaba }\end{array}$ \\
\hline $\begin{array}{l}\text { Campo das } \\
\text { Vertentes }\end{array}$ & $\begin{array}{l}\text { Queijo Minas } \\
\text { Artesanal }\end{array}$ & $\begin{array}{c}\text { Barroso, Conceição da Barra de Minas, Coronel Xavier } \\
\text { Chaves, Carrancas, Lagoa Dourada, Madre de Deus de } \\
\text { Minas, Nazareno, Prados, Piedade do Rio Grande, Resende } \\
\text { Costa, Ritápolis, Santa Cruz de Minas, São João Del Rei, } \\
\text { São Tiago e Tiradentes }\end{array}$ \\
\hline Cerrado & $\begin{array}{l}\text { Queijo Minas } \\
\text { Artesanal do } \\
\quad \text { Cerrado }\end{array}$ & $\begin{array}{l}\text { Abadia dos Dourados, Arapuá, Carmo do Paranaíba, } \\
\text { Coromandel, Cruzeiro da Fortaleza, Guimarânia, Lagamar, } \\
\text { Lagoa Formosa, Matutina, Patos de Minas, Patrocínio, } \\
\text { Presidente Olegário, Rio Paranaíba, Santa Rosa da Serra, } \\
\text { São Gonçalo do Abaeté, São Gotardo, Tiros, Varjão de } \\
\text { Minas, Vazante. }\end{array}$ \\
\hline $\begin{array}{l}\text { Serra do } \\
\text { Salitre }\end{array}$ & $\begin{array}{l}\text { Queijo } \\
\text { Salitre Minas } \\
\text { Artesanal }\end{array}$ & Serra do Salitre \\
\hline Serro & $\begin{array}{l}\text { Queijo Minas } \\
\text { do Serro }\end{array}$ & $\begin{array}{l}\text { Alvoradas de Minas, Conceição do Mato Dentro, Dom } \\
\text { Joaquim, Materlândia, Paulistas, Rio Vermelho, Sabinópolis, } \\
\text { Santo Antônio do Itambé, Serra Azul de Minas, Coluna, } \\
\text { Serro. }\end{array}$ \\
\hline $\begin{array}{l}\text { Triângulo } \\
\text { Mineiro }\end{array}$ & $\begin{array}{l}\text { Queijo Minas } \\
\text { Artesanal }\end{array}$ & $\begin{array}{c}\text { Araguari, Cascalho Rico, Estrela do Sul, Indianópolis, } \\
\text { Monte Alegre de Minas, Monte Carmelo, Nova Ponte, } \\
\text { Romaria, Tupaciguara e Uberlândia. }\end{array}$ \\
\hline $\begin{array}{l}\text { Vale do } \\
\text { Jequitinhonha }\end{array}$ & $\begin{array}{l}\text { Queijo } \\
\text { Cabacinha }\end{array}$ & $\begin{array}{l}\text { Pedra Azul, Medina, Cachoeira do Pajeú, Comercinho e } \\
\text { Itaobim }\end{array}$ \\
\hline $\begin{array}{l}\text { Vale do } \\
\text { Suaçuí }\end{array}$ & $\begin{array}{l}\text { Queijo } \\
\text { Parmesão } \\
\text { Artesanal }\end{array}$ & $\begin{array}{c}\text { Água Boa, Frei Lagonegro, José Raydan, Santa Maria do } \\
\text { Suaçuí, São José do Jacurí, São Pedro do Suaçuí e São } \\
\text { Sebastião do Maranhão }\end{array}$ \\
\hline
\end{tabular}

Fonte: Compilado de IMA (2016) 
propriedade de origem e que, ao final, apresente todas as características físico-químicas, microbiológicas, sensoriais e de textura dos queijos artesanais.

Portanto, existem diferentes tipos de "Queijo Minas Artesanal", tendo sido cadastrados até o momento sete regiões do estado como produtoras, sendo essas: Araxá, Canastra, Campo das Vertentes, Cerrado, Serra do Salitre, Serro, Triângulo Mineiro. O Vale do Jequitinhonha e Vale do Suaçuí são consideradas como produtoras de "Queijo Artesanal", sendo definidos pela Lei $\mathrm{n}^{\circ} 20.549$ de 18 de dezembro de 2012 como aqueles produzidos com leite de vaca, sem tratamento térmico da massa, como o queijo Minas artesanal e o queijo meia-cura e, também, os produzidos com leite de vaca, com tratamento térmico da massa, como o queijo Cabacinha e o requeijão artesanal (MINAS GERAIS, 2012). Esta Lei foi posteriormente revogada pela Lei $\mathrm{n}^{\circ} 23.157$ de 18 de dezembro de 2012, em que o queijo artesanal é considerado aquele elaborado com leite integral fresco e cru e com características de identidade e qualidade específicas (MINAS GERAIS, 2018). A Tabela 1 resume as regiões produtoras de Queijo Artesanal e cidades autorizadas, cadastradas no Instituto Mineiro de Agropecuária (IMA).

A Região do Vale do Jequitinhonha foi reconhecida pelo IMA apenas em 2014 para produção do queijo artesanal Cabacinha, com o intuito de incentivar e legalizar a produção, agregando dessa forma valor ao produto e promovendo geração de renda para os agricultores locais (IMA, 2014). De acordo com o mesmo Instituto, foram considerados nessa legislação todos os fatores regionais, tais como o tipo de solo, clima, sistema de produção, alimentação do rebanho, assim como as carências enfrentadas na região, pois são aspectos fundamentais que influenciam e caracterizam a textura, coloração e sabor do queijo (FAEMG, 2014).
Historicamente, a introdução do queijo Cabacinha no Vale do Jequitinhonha está relacionada com aspectos econômicos como a baixa produção leiteira e a dificuldade de escoamento do leite ordenhado (FURUYA, 2010). Muitos produtores optam então pela fabricação do queijo, de forma caseira, contribuindo como fonte de renda para as famílias locais. A produção é comumente realizada pelos próprios agricultores, em condições caseiras, os quais são responsáveis por todo processo, desde a obtenção do leite, produção, até a comercialização (ARAÚJO, 2017).

Tradicionalmente, a comercialização desse queijo ocorre em barracas montadas nas proximidades de vias urbanas e rodovias, diretamente expostas ao ambiente, sem proteção contra insetos e poeira. A maioria dos produtores também não possuem treinamento e condições adequadas para manipulação de alimentos, o que pode representar um problema de saúde pública devido ao risco de contaminação e veiculação de agentes patogênicos (SANTOS FILHO et al., 2016).

Diante do exposto, esse trabalho teve como objetivo realizar um estudo de viabilidade econômica e financeira de um projeto de agroindústria familiar para a fabricação do queijo artesanal Cabacinha no Vale do Jequitinhonha, em condições adequadas de boas práticas de fabricação, respeitando a legislação vigente e visando agregar valor e qualidade a produção local. Foram abordados os aspectos mercadológicos, operacionais e financeiros do projeto, utilizando indicadores que podem nortear os produtores locais na implantação da agroindústria e na tomada de decisões.

\section{MATERIAL E MÉTODOS}

Para a realização do trabalho foram abordados os aspectos mercadológicos e operacionais da produção do queijo artesanal 
Cabacinha, indicando as condições que devem ser respeitadas para a construção das instalações e para o processamento do leite até sua transformação no queijo, baseando-se em legislações estaduais e federais. No projeto financeiro, foi elaborada uma projeção do fluxo de caixa da empresa para os primeiros anos de atividade, bem como calculados a lucratividade, rentabilidade, Valor Presente Líquido, Taxa Interna de Retorno e o Payback.

\section{RESULTADOS E DISCUSSÃO}

\section{Aspectos mercadológicos e operacionais da produção}

De acordo com os dados de Furuya (2010), 97,4\% da produção do queijo Cabacinha é familiar, sendo que $50 \%$ dos produtores processam até 65 litros de leite por dia, 37,5\% produzem entre 65 a 185 litros de leite por dia e $12,5 \%$ entre 186 e $300 \mathrm{~L} /$ dia. É um queijo reconhecido pelo sabor e textura característicos, com certa semelhança com a produção do queijo muçarela, já que também é utilizado aquecimento da massa, no entanto, a matéria-prima não é pasteurizada.

De forma geral, o processamento ideal de produção do queijo Cabacinha, conforme indicado por Furuya (2010), inicia com a filtração do leite recém ordenhado, utilizando tecido sintético higienizado. O fermento natural, denominado de "pingo", é a cultura lática adicionada ao leite que promove juntamente com o coalho a coagulação da massa, sendo responsável também pelo sabor característico do queijo. Após a coagulação, é realizado o corte da massa, a qual é posteriormente aquecida a $40{ }^{\circ} \mathrm{C}$, com mexedura para auxiliar na dessoragem até atingir o ponto adequado; durante este processo o "pingo" é recolhido e utilizado na próxima produção. Após o escoamento do soro, ocorre a fermentação natural por 12 a 24 horas, sendo então feita a filagem e moldagem da massa manualmente no formato de Cabacinha. Após esta fase é realizada a salga por imersão em salmoura. O queijo é maturado por 7 dias, sendo então comercializado. Na Figura 1 é representado o fluxograma de processamento. Deve ser ressaltado que, por não existir uma legislação que regulamenta o modo de fabricação do queijo Cabacinha, existem grandes variações no modo de produção, o que impacta também na qualidade final dos produtos

O queijo Cabacinha é considerado uma versão brasileira do queijo "Caccio Cavalo", de origem italiana (SANTOS FILHO et al., 2016), como pode ser observado na Figura 2.

Para garantir a qualidade do queijo artesanal, o IMA (2016) determina que a fabricação deva ocorrer com o leite recémordenhado, onde o produtor tenha um controle sanitário do rebanho, atendendo a legislação estadual vigente. A queijaria deve possuir um banheiro com saída independente, uma entrada para higienização de mãos e botas,

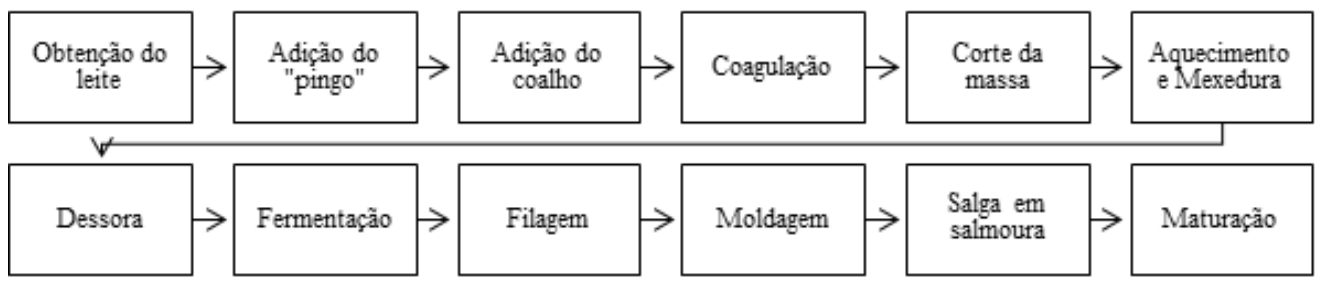

Figura 1 - Fluxograma proposto para produção de queijo artesanal Cabacinha

Fonte: Adaptado de Minas Gerais (2012). 
sala de fabricação, sala de maturação, sala de embalagem e expedição. Com base em tais recomendações foi elaborado um layout de um estabelecimento de produção, de acordo com as condições mínimas para produção do queijo Cabacinha em adequadas condições de boas práticas de fabricação, apresentado na Figura 3.

De acordo com a Portaria $n^{\circ} 518$, de
14 de junho de 2002 do IMA, as instalações da queijaria deverão possuir dimensões físicas compatíveis com os trabalhos a serem realizados, sendo considerado no presente projeto uma área total de $20 \mathrm{~m}^{2}$. As instalações devem conter ventilação e iluminação adequadas, construção em alvenaria e estrutura apropriada para a limpeza e sanitização dos utensílios. Os

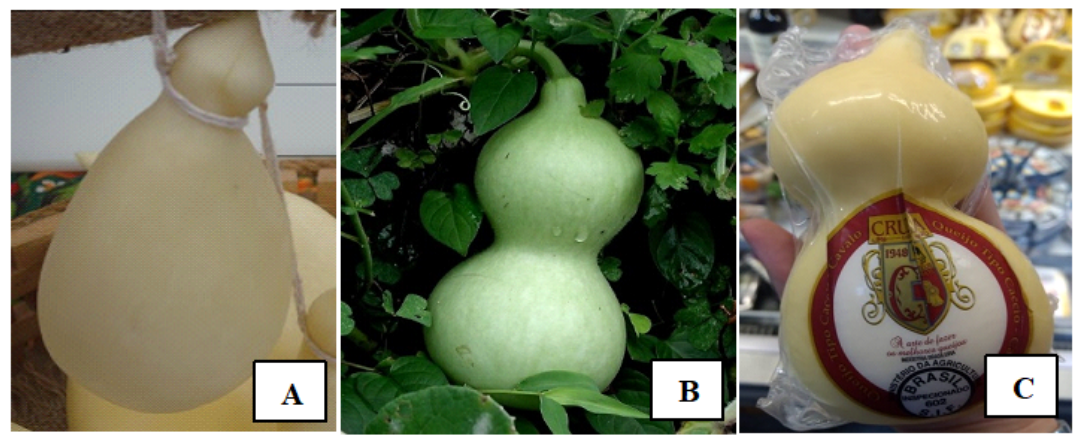

Figura 2 - Queijo Cabacinha (A), cabaça (Lagenaria siceraria) (B) e queijo Caccio Cavalo (C), respectivamente

Fontes: A e C - os autores; B - www.publicdomainpictures.net

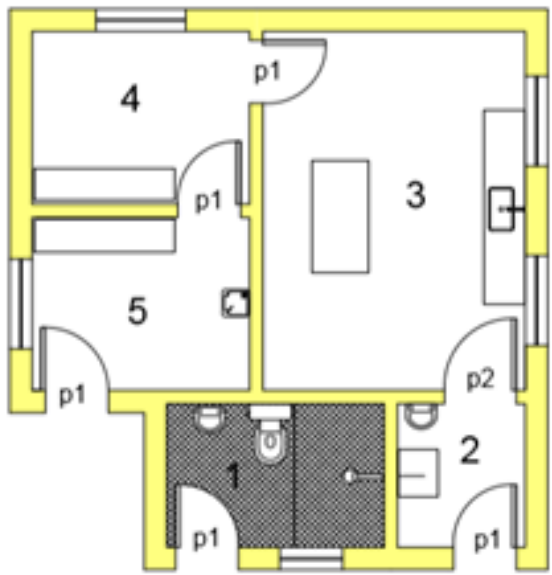

Figura 3 - Proposta de Layout de estabelecimento de produção do queijo Cabacinha (queijaria) apresentando condições adequadas para implementação de boas práticas de fabricação (5,5 $\mathrm{m}$ x 5,5 m, comprimento x largura). Legenda: 1: Banheiro $\left(3 \mathrm{~m}^{2}\right), 2$ : Entrada $\left(1,5 \mathrm{~m}^{2}\right)$, 3: Sala de Fabricação $\left(12 \mathrm{~m}^{2}\right)$, 4: Sala de Maturação $\left(5 \mathrm{~m}^{2}\right)$, 5: Sala de Embalagem $\left(5 \mathrm{~m}^{2}\right)$ 
manipuladores deverão usar equipamentos de proteção individual adequados às suas atividades, como roupa protetora branca, botas brancas, máscara para boca e nariz e touca protetora, laváveis ou descartáveis (EMATER, 2009).

Para evitar contaminação dos queijos, os equipamentos, utensílios e todas as superfícies que entrarem em contato com o alimento deverão ser limpos imediatamente após o uso com água, detergentes, desinfetantes ou soluções destes, para serem utilizadas novamente para manipulação. O queijo somente deverá ser embalado após a maturação, sendo recomendado possuir umidade inferior a 46\%, utilizando embalagem plástica própria para contato com alimento (EMATER, 2009).

Atualmente, na região do Vale do Jequitinhonha, existem cerca de 100 produtores do queijo Cabacinha em sistema familiar. A formalização da produção através de agroindústrias familiares, além de gerar emprego e renda, contribui na preservação da identidade cultural e culinária da região (ARAÚJO, 2017). Da mesma forma, deve-se compreender o comportamento do consumidor desse queijo para que o produto seja absorvido pelo mercado.

Além dos atributos nutricionais e gastronômicos presentes nos alimentos, o tipo de embalagem, a praticidade e o preço influenciam na escolha de um produto. Analisar os concorrentes e fornecedores possibilita identificar e dimensionar problemas ou necessidades, bem como, dimensionar o mercado e o volume que o mesmo é capaz de absorver (SEBRAE, 2013).

O mercado do queijo Cabacinha é formado por consumidores que apreciam alimentos regionais. Além de pontos de vendas na margem de rodovias e em feiras livres na região do Vale do Jequitinhonha, os queijos são levados para Araçuaí, Governador Valadares, Almenara, Montes Claros e também são comercializados em São Paulo. No mercado central de Belo Horizonte foi verificado o preço de venda médio de $\mathrm{R} \$ 28,00 / \mathrm{kg}$.

\section{Aspectos financeiros da produção}

O projeto de investimento financeiro possibilita analisar os riscos do investimento, verificar se os resultados futuros justificam o custo de implementação, quais serão os lucros obtidos, dentre outros, facilitando nas tomadas de decisões e na projeção do fluxo de caixa da empresa (LAPPONI, 2007). Nesse projeto foi considerado um volume diário de $125 \mathrm{~L}$ de leite, possibilitando uma produção de 25 unidades diárias do queijo, com peso unitário médio de $400 \mathrm{~g}$.

O rendimento de produção considerado foi de $12,5 \mathrm{~L}$ de leite/ $\mathrm{kg}$ de queijo pronto. Deve ser ressaltado que, por ser um produto artesanal está sujeito a fatores que podem interferir na produção, tais como a variação do clima, flutuação no volume de leite, capacitação do manipulador, dentre outros. Os dados considerados para o desenvolvimento dessa pesquisa são médias obtidas a partir de uma pesquisa de mercado com dados secundários da região, baseando-se em levantamentos e relatórios do Instituto Brasileiro de Geografia e Estatística (IBGE, 2015) e EMATER-MG (2015).

$\mathrm{O}$ investimento pré-operacional para a construção da queijaria é previsto em $\mathrm{R} \$$ 43.816,00; sendo 70,35\% desse valor destinado à construção da unidade agroindustrial, em conformidade com a legislação para produção de alimentos e, 29,65\% serão destinados a aquisição de equipamentos e utensílios, descritos na Tabela 2.

A edificação, instalações, layout, fluxo de processo, disposição de equipamentos, dentre outros, seguirá as normas da Portaria $\mathrm{n}^{\circ}$ 326, de 30 de julho de 1997, do Ministério da Saúde (BRASIL, 1997), bem como RDC n ${ }^{\circ} 275$ de 21 de outubro de 2002, do Ministério da Saúde (BRASIL, 2002). Para 
o cálculo de gastos com construção, foi utilizado o valor do Custo Unitário Básico da Construção Civil (CUB/m2 Padrão Normal R-1) para a região do Norte de Minas, (dados de janeiro de 2019 da SINDUSCON Norte) equivalente a $\mathrm{R} \$ 1.520,55 / \mathrm{m}^{2}$ (CBIC, 2019). Os investimentos pré-operacionais com obras civis e registro de marca, necessários para construção da queijaria é de $\mathrm{R} \$ 30.826,00$.

Para o cálculo do custo de produção foi considerada a utilização do leite ordenhado no próprio estabelecimento rural, ao custo de $\mathrm{R} \$ 0,90 / \mathrm{L}$. A salmoura utilizada para salga dos queijos deverá ser trocada duas vezes por mês, sendo elaborada na concentração de $20 \%$ de sal para 1 litro de água.

Para uma adequada limpeza e higienização das instalações é necessário um sistema de abastecimento de água potável, com apropriada pressão e distribuição, sendo gasto para cada litro de leite processado, cinco litros de água. O valor do custo com água e esgoto foram baseados nas tarifas da Companhia de Saneamento de Minas Gerais (COPASA - MG), responsável pelo abastecimento de água na região, com o valor equivalente de $\mathrm{R} \$ 8,528 / \mathrm{m}^{3}$ e uma taxa de esgoto de R $\$ 8,086 / \mathrm{m}^{3}$ (ARSAE - MG, 2018).

De acordo com os dados da Companhia Energética de Minas Gerais S.A(CEMIG), foi realizado o custo com energia elétrica para produção, sendo na área rural $\mathrm{R} \$ 0,4179 / \mathrm{KWh}$ (CEMIG, 2018). Dessa forma, considerando a produção diária de 25 unidades de $400 \mathrm{~g}$ durante 30 dias no mês, o custo total anual é estimado em $\mathrm{R} \$ 49.400,18$, com volume de produção de 9.000 queijos. Assim, o custo unitário do produto é estimado em $\mathrm{R} \$ 5,49$, sendo o preço de venda de $\mathrm{R} \$ 9,50$ a unidade de 400 g. Tal preço de venda está coerente com o praticado na região, sendo pago pelos

Tabela 2 - Lista proposta para aquisição de equipamentos, utensílios e acessórios para a queijaria

\begin{tabular}{lr}
\hline Itens & Total (R\$) \\
\hline Acessórios para banheiro (porta toalha, lixeira, chuveiro) & 250,00 \\
Lavatório para as mãos & 400,00 \\
Lava botas manual & 600,00 \\
Vaso sanitário & 200,00 \\
Caixa d'água (1000 L) & 300,00 \\
Lâmpadas e acessórios & 100,00 \\
EPI's (botas, uniformes, avental) & 200,00 \\
Tanques para recepção e coagulação do leite (200L) & $7.000,00$ \\
Pia de aço inox & 150,00 \\
Mesa de aço inox & $1.200,00$ \\
Facas, funil, pás, liras, acessórios & 900,00 \\
Prateleiras & $1.000,00$ \\
Seladora automática a vácuo (285W) & 490,00 \\
\hline Total & $\mathbf{1 2 . 9 9 0 , 0 0}$ \\
\hline
\end{tabular}


intermediários que adquirem os produtos na região do Vale do Jequitinhonha e o revendem para os consumidores a aproximadamente R\$ 11,50. Na Tabela 3 estão apresentados os itens que compõem a formação do custo de produção.

Considerou-se o financiamento do investimento pré-operacional, juntamente com o capital de giro ( $\mathrm{R} \$ 8.233,36)$, necessário para início das atividades e movimentação da empresa por 2 meses sem retorno financeiro, através da linha de crédito do Programa de Fortalecimento da Agricultura Familiar PRONAF (BNDES, 2018), a uma taxa de juros anual de 4,6\% em sistema de amortização constante (SAC), com financiamento em 10 anos e período de carência de 3 anos, conforme apresentado na Tabela 4 .

Para avaliação tributária foi utilizado o sistema Simples Nacional, estando incluídos os impostos IRPJ, CSLL, PIS, CONFINS, IPI, CPP, ISS, ICMS. Através da projeção do Demonstrativo do Resultado do Exercício (DRE), que pode ser observada no primeiro ano de atividades apresentado na Tabela 5 , com o cálculo de todas as receitas da agroindústria, bem como os custos e despesas, incluindo os impostos, dentre outros, é previsto para o primeiro ano um lucro líquido de $38,32 \%$.

O ponto de equilíbrio previsto para o primeiro ano é atingido com a venda de 5.537 unidades, sendo esse o momento no qual o faturamento bruto da empresa gera lucro suficiente para o pagamento dos custos e despesas, ou seja, a empresa não gera lucro nem prejuízo. Tal valor repete-se até o terceiro ano, sendo que, no quarto ano iniciase o pagamento de juros e amortização do empréstimo, elevando o ponto de equilíbrio para 6.696 unidades anuais. Esse valor diminui gradativamente do quarto ao décimo ano, devido à diminuição das parcelas do financiamento, sendo equivalente a 6.454

Tabela 3 - Gastos mensais estimados com matéria-prima e demais insumos necessários para produção do queijo artesanal Cabacinha

\begin{tabular}{lcc}
\hline \multicolumn{1}{c}{ Item } & Quantidade & Valor mensal (R\$) \\
\hline Leite in natura & $3750 \mathrm{~L}$ & $3.375,00$ \\
Coalho & $0,75 \mathrm{~L}$ & 26,10 \\
Sal & $4 \mathrm{Kg}$ & 9,80 \\
Embalagem & $810 \mathrm{un}$. & 125,10 \\
Gás & $13 \mathrm{Kg}$ & 70,00 \\
Água & $18,75 \mathrm{~m}^{3}$ & 159,47 \\
Tratamento de esgoto & $18,75 \mathrm{~m}^{3}$ & 151,21 \\
Energia elétrica & $122 \mathrm{~kW} / \mathrm{h}$ & 50,00 \\
Produtos de limpeza & $5 \mathrm{un}$. & 150,00 \\
\hline Total & & $4.116,68$ \\
\hline
\end{tabular}


unidades no décimo ano, finalizando o pagamento do empréstimo.

A movimentação financeira da empresa foi projetada para os 10 anos iniciais da agroindústria, na forma de fluxo de caixa (FC). A projeção do $\mathrm{FC}$ permite simular todas as entradas e as saídas de recursos financeiros que a empresa terá no horizonte planejado, demonstrando qual será a situação da empresa nesse período, bem como, permitindo calcular determinados indicadores financeiros do projeto. Na Tabela 5 é apresentada a projeção do FC da queijaria.

A lucratividade anual esperada do primeiro ao terceiro ano é de $38,32 \%$, e a partir do quarto ano de $25,4 \% ; 25,84 \%$; $26,29 \% ; 26,73 \% ; 27,18 \%, 27,62 \%$ e $28,06 \%$ respectivamente. Percebe-se a diminuição a partir do quarto ano devido ao início do pagamento do financiamento, o qual reduz a lucratividade em cerca de $33,72 \%$. A rentabilidade anual do primeiro ao terceiro ano é de $62,95 \%$, e a partir do quarto ano até o décimo, devido ao financiamento, a rentabilidade é de $41,72 \% ; 42,45 \%$; $43,18 \% ; 43,91 \%$; $44,64 \% ; 45,37 \%$ e $46,10 \%$ respectivamente.

Ao trazer os valores de caixa líquido para o presente, considerando uma taxa mínima de atratividade (TMA) de $20 \%$, é possível verificar que o valor presente Líquido (VPL) do negócio é equivalente a R \$ $64.077,25$ e o payback descontado ocorre em 2 anos e 1 mês após o início das atividades da queijaria, representando o tempo necessário para recuperar o investimento inicial. A taxa interna de retorno (TIR) do projeto é de 57,3\% e, juntamente com os demais indicadores financeiros, pode-se concluir que o cenário apresentado nesse trabalho para a implantação da queijaria permite um investimento de baixo risco e que resultará em lucro líquido de cerca de $\mathrm{R} \$ 2.730,21$ mensais ao produtor rural do primeiro ao terceiro ano e, de cerca de $\mathrm{R} \$ 1.809,65$ a partir do quarto ano de atividades.

Deve ser ressaltado que a elaboração

Tabela 4 - Previsão de despesas anuais com juros e amortização gerados pelo empréstimo de valores referentes ao investimento pré-operacional e capital de giro, necessários para a implantação da queijaria artesanal

\begin{tabular}{cc}
\hline Ano & Despesas com juros e amortização \\
\hline 01 & $\mathrm{R} \$ 0,00$ \\
02 & $\mathrm{R} \$ 0,00$ \\
03 & $\mathrm{R} \$ 0,00$ \\
04 & $\mathrm{R} \$ 11.018,11$ \\
05 & $\mathrm{R} \$ 10.634,66$ \\
06 & $\mathrm{R} \$ 10.251,22$ \\
07 & $\mathrm{R} \$ 9.867,77$ \\
08 & $\mathrm{R} \$ 9.484,32$ \\
09 & $\mathrm{R} \$ 9.100,87$ \\
10 & $\mathrm{R} \$ 8,717,42$ \\
11 & $\mathrm{R} \$ 0,00$ \\
\hline
\end{tabular}




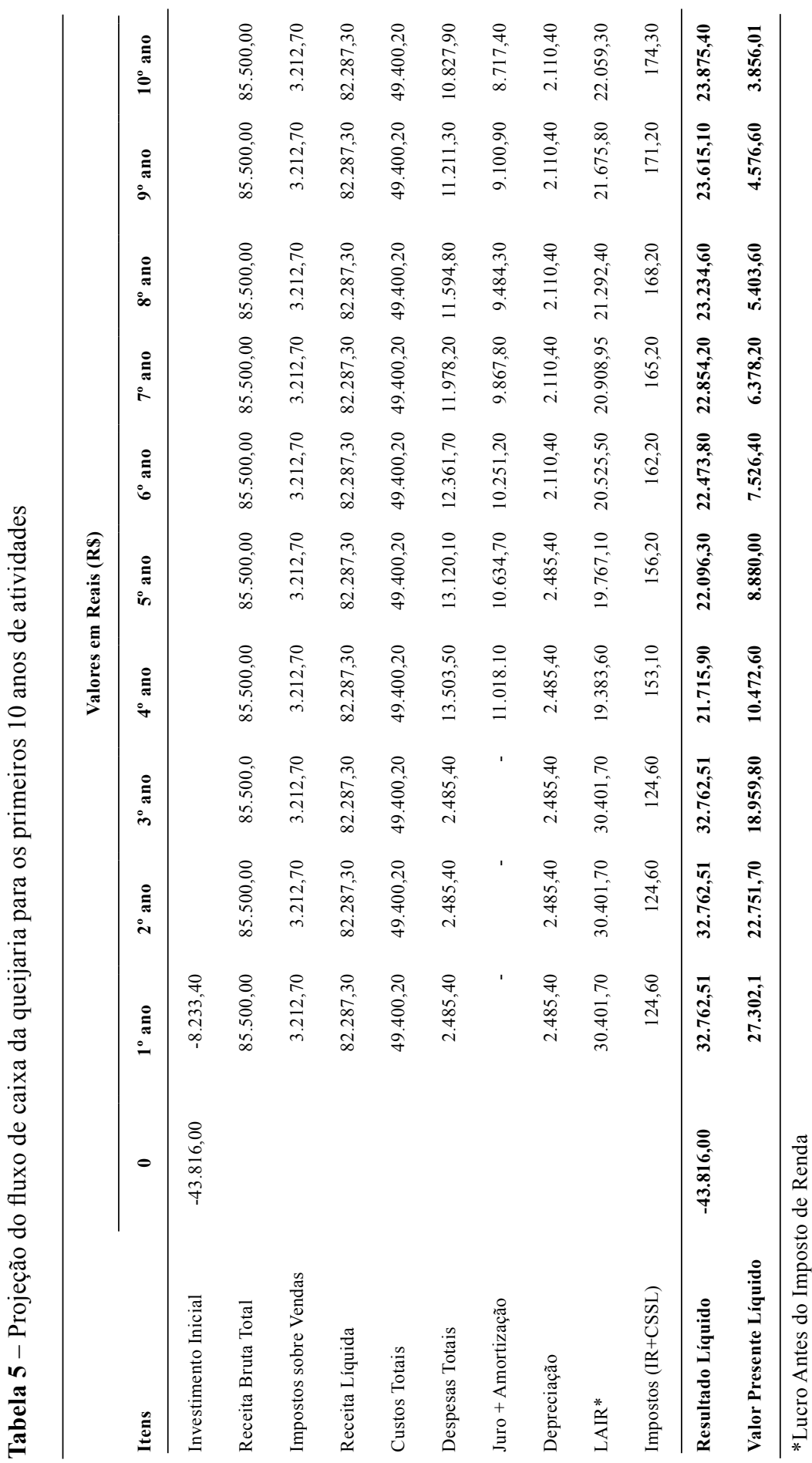


do queijo Cabacinha através de um processo de fabricação regulamentado, em condições adequadas de boas práticas de fabricação, permite maior agregação de valor ao produto, podendo ser comercializado por um preço diferenciado entre os concorrentes.

Considerando um cenário pessimista, poderá ocorrer a queda da produção de leite, devido às condições climáticas, afetando diretamente no volume de produção do queijo. Por outro lado, em um cenário otimista, poderá ocorrer o aumento do volume ordenhado, aumentando o volume de produção e, consequentemente, gerando melhores retornos financeiros. Acredita-se que, ao oferecer para o mercado produtos de melhor qualidade e padronizados, a demanda pelo queijo Cabacinha aumente, já que esse queijo ainda é pouco conhecido mesmo dentro do estado de Minas Gerais.

Para uma maior rentabilidade do projeto, sugere-se ao produtor rural aumentar o volume de produção, dentro de suas possibilidades, bem como uma maior divulgação do produto, sua história e tradição regional, fortalecendo assim a cultura gastronômica e agroindustrial do Vale do Jequitinhonha.

\section{CONCLUSÕES}

A partir dos levantamentos e cenários projetados nesse estudo, pode-se concluir que é viável o investimento financeiro para a construção da queijaria artesanal, visando a produção do queijo Cabacinha em regime de agroindústria familiar de pequena escala na região do Vale do Jequitinhonha. A produção do queijo Cabacinha irá proporcionar ao produtor rural maior valorização do leite, uma vez que, tal matéria-prima será transformada em um produto de maior valor comercial, possibilitando também a geração de trabalho e renda na propriedade rural. A queijaria artesanal também irá contribuir na produção de alimentos seguros para o consumidor, elaborados em condições adequadas de higiene, bem como, respeitando as tradições locais.

\section{REFERÊNCIAS}

ARAUJO. L. F. Reconhecimento do queijo Cabacinha (tipo Muçarela) no Mercado Central de Belo Horizonte. Trabalho de Conclusão de Curso (Bacharelado em Engenharia de Alimentos) - Universidade Federal de São João del-Rei, Sete Lagoas, 2017.

ARSAE - MG. Agência Reguladora de Servicos de Abastecimento de Água e de Esgotamento Sanitário do Estado de Minas Gerais. Resolução Normativa $n^{0} 111$ de 28 de junho de 2018. Autoriza a Copasa a aplicar aos serviços públicos de abastecimento de água e de esgotamento sanitário prestados as tarifas constantes do Anexo desta Resolução e dá outras providências. Belo Horizonte: ARSAE-MG, 2018. Disponível em: http:// www.arsae.mg.gov.br/images/documentos/ audiencia_publica/Resolucao_ 111 ReajusteCopasa_2018.pdf Acesso em: 28 nov. 2018.

BNDES. Banco Nacional de Desenvolvimento Econômico e Social. Programa de Fortalecimento da Agricultura Familiar - PRONAF. Rio de Janeiro: BNDES, 2018. Disponível em: https://www.bndes.gov.br/ wps/portal/site/home/financiamento/produto/ pronaf Acesso em: 30 out. 2018.

BRASIL. Ministério da Saúde. Secretaria de Vigilância Sanitária. Portaria n ${ }^{\circ} 326$, de 30 de julho de 1997. Aprova o Regulamento Técnico "Condições Higiênicos-Sanitárias e de Boas Práticas de Fabricação para Estabelecimentos Produtores/Industrializadores de Alimentos". Diário Oficial da União: seção 1, Brasília, DF, n. 120, p. 13, 1 ago. 1997.

BRASIL. Ministério da Saúde. Agência 
Nacional de Vigilância Sanitária. Resolução RDC no 275, de 21 de outubro de 2002. Dispõe sobre o Regulamento Técnico de Procedimentos Operacionais Padronizados aplicados aos Estabelecimentos Produtores/ Industrializadores de Alimentos e a Lista de Verificação das Boas Práticas de Fabricação em Estabelecimentos Produtores/ Industrializadores de Alimentos. Diário Oficial da União: seção 1, Brasília, DF, n. 215, p. 55,06 nov. 2002 .

CBIC. Câmara Brasileira da Indústria da Construção. CUB/m² Custo Unitário Básico. Indicador dos custos do setor da Construção Civil. Disponível em: http://www.cub.org.br/ cub-m2-estadual/MG/ Acesso em: 16 jan. 2019.

CEMIG. Companhia Energética de Minas Gerais. Valores de tarifas e serviços. 2018. Disponível em: https://www.cemig.com.br/ptbr/atendimento/Paginas/valores_de_tarifa_e_ servicos.aspx Acesso em: 02 fev.2018.

DORES, M. T., FERREIRA, C. L. L. F. Queijo Minas Artesanal, tradição centenária: ameaças e desafios. Revista Brasileira de Agropecuária Sustentável, v. 2, n. 2, p. 26-34, 2012.

EMATER-MG. Empresa de Assistência Técnica e Extensão Rural do Estado de Minas Gerais. Programa Queijo Minas Artesanal. 2015. Disponível em: http://www. emater.mg.gov.br/portal.do?flagweb $=$ site tpl_queijo\&id=3301 Acesso em: 22 jul. 2020.

EMATER-MG. Empresa de Assistência Técnica e Extensão Rural do Estado de Minas Gerais. Queijo Minas Artesanal. Guia técnico para implantação de boas práticas de fabricação em unidades de produção do queijo minas artesanal. 2009. Disponível em: http:// www.emater.mg.gov.br/doc/intranet/upload/
QUEIJO_SITE/cartilha_queijo\%202.pdf Acesso em: 22 jul. 2020.

EMATER-MG. Empresa de Assistência Técnica e Extensão Rural do Estado de Minas Gerais. Produção de queijo Minas artesanal ganha reforço com o atendimento a 600 produtores familiares no estado. Belo Horizonte: EMATER, 2017. Disponível em: http://www.emater.mg.gov. br/portal.cgi?flagweb=novosite_pagina interna\&id=20360 Acesso em: 24 jun. 2018.

FAEMG. Federação da Agricultura e Pecuária do Estado de Minas Gerais. Queijo Cabacinha será padronizado. Belo Horizonte: FAEMG, 2014. Disponível em: http://www.faemg.org. br/Noticia.aspx ?Code $=5878 \&$ ContentVersio $\mathrm{n}=\mathrm{C} \&$ Show $=$ all

Acesso em: 6 set. 2018.

FURUYA, L. B. Identidade e qualidade do queijo de massa cozida do nordeste mineiro. 2010. 117 f. Dissertação (Mestrado em Ciência de Alimentos) - Faculdade de Farmácia, Universidade Federal de Minas Gerais, Belo Horizonte, Minas Gerais, 2010.

IBGE. Instituto Brasileiro de Geografia e Estatística. Pecuária. Panorama das cidades: Uberlândia.2015. Disponível em: http:// cidades.ibge.gov.br/xtras/perfil.php?lang=\&c odmun $=317020 \&$ search $=$ minas-gerais Acesso em: 30 jul. 2018.

IMA. Instituto Mineiro de Agropecuária. Portaria $n^{0}$ 523, de 3 de julho de 2002. Dispõe sobre as condições higiênico-sanitárias e boas práticas na manipulação e fabricação do Queijo Minas Artesanal. Belo Horizonte: IMA, 2002.

IMA. Instituto Mineiro de Agropecuária. Portaria $n^{0}$ 1403, de 02 de maio 2014. Identifica a região do Vale do Jequitinhonha 
como produtora de queijo Cabacinha. Belo Horizonte: IMA, 2014.

IMA. Instituto Mineiro Agropecuário. Queijos Artesanais. Belo Horizonte: IMA, 2016. Disponível em: http://www.ima.mg.gov.br/ agroindustria/queijos-artesanais Acesso em: 30 jul. 2018.

IPHAN. Instituto do Patrimônio Histórico e Artístico Nacional. Modo Artesanal de Fazer Queijo de Minas. Brasília: IPHAN, 2014. Disponível em: http://portal.iphan.gov. br/mg/pagina/detalhes/65 Acesso em: $30 \mathrm{de}$ jun. 2018.

LAPONNI, J. C. Projetos de Investimento na Empresa. Rio de Janeiro: Elsevier, 2007.

MINAS GERAIS. Lei Estadual $\mathrm{n}^{\circ} 23.157$, de 18 de dezembro de 2018. Dispõe sobre a produção e a comercialização dos queijos artesanais de Minas Gerais. Minas Gerais Diário do Executivo: col 1, Belo Horizonte, MG, p. 01, 19 dez 2018.

MINAS GERAIS. Lei $\mathrm{n}^{\circ}$ 20.549, de 18 de dezembro de 2012. Dispõe sobre a produção e a comercialização dos queijos artesanais de Minas Gerais. Diário do Executivo do Estado de Minas Gerais: caderno 1, Belo Horizonte, MG, n. 236, p. 1, 19 dez. 2012.

SANTOS FILHO, A. et al. Caracterização física e condições sanitárias do comércio de queijo Cabacinha em três municípios do Vale do Jequitinhonha, MG, Brasil. Revista do Instituto de Laticínios Cândido Tostes, v. 71, n. 4 , p. 219-227, 2016.

SEBRAE. Serviço Brasileiro de Apoio às Micro e Pequenas Empresas. Como Elaborar um Plano de Negócios. Brasília: SEBRAE, 2013. 